\title{
sciendo
}

\section{IN VITRO ANTIOXIDANT ACTIVITY OF ARTEMISIA ARGYI POWDER AND THE EFFECT ON HEPATIC AND INTESTINAL ANTIOXIDANT INDICES IN BROILER CHICKENS*}

\author{
Pengfei Zhang ${ }^{1,2 \dagger}$, Hongyan Chen ${ }^{1 \dagger}$, Binlin Shi ${ }^{1}$, Fei Zhao ${ }^{1}$, Xiaoyu Guo ${ }^{1}$, Xiao Jin ${ }^{1}$, Sumei Yan ${ }^{1}$ \\ ${ }^{1}$ College of Animal Science, Inner Mongolia Agricultural University, Hohhot 010018, P.R. China \\ ${ }^{2}$ Department of Medical Laboratory, Shenzhen Longhua District Central Hospital, \\ Affiliated Center Hospital of Shenzhen Longhua District, Guangdong Medical University, \\ Shenzhen 518110, Guangdong, China \\ •Corresponding author: shibinlin@yeah.net
}

\begin{abstract}
This study was conducted to investigate the in vitro and in vivo antioxidant effect of Artemisia argyi powder (AAP). Two hundred forty mixed-sex one-day-old Arbor Acres broilers were randomly divided into five treatment groups, each consisting of six replicates (one replicate per cage) with eight broilers per replicate. Broilers were fed basal diets supplemented with $0,2.5,5,10$ and 20 g AAP per $\mathrm{kg}$ feed, respectively. The hepatic and intestinal samples were collected on $\mathrm{d} 21$ and 42 for analysis of antioxidant indices and antioxidative enzyme gene expression. The in vitro results showed that the scavenging activity of Artemisia argyi against $\bullet \mathrm{OH}$ and DPPH were $34.99 \pm 1.11 \%$ and $74.12 \pm 0.50 \%$, respectively; the ferric reducing power was $2.58 \pm 0.03 \%$. The in vivo results showed that dietary $20 \mathrm{~g} / \mathrm{kg}$ of AAP significantly enhanced the hepatic total antioxidant capacity (T-AOC), catalase (CAT) activity, and glutathione peroxidase (GSH-Px) activity, also decreased the malondialdehyde (MDA) content; dietary10 $\mathrm{g} / \mathrm{kg}$ of AAP significantly increased the gene expression of superoxide dismutase (SOD) and CAT on d 42. For the duodenum, $10 \mathrm{~g} / \mathrm{kg}$ of AAP increased SOD activity $(\mathrm{P}<0.05)$, and reduced MDA level $(\mathrm{P}<0.05)$ on $\mathrm{d} 21$; the gene expression of CAT and SOD were increased in the $20 \mathrm{~g} / \mathrm{kg}$ of AAP treatment compared with the control group on $\mathrm{d} 42$. For the jejunum, on $\mathrm{d} \mathrm{21}$, the T-AOC level was increased by inclusion of $10 \mathrm{~g} / \mathrm{kg}$ of AAP, and CAT activity was enhanced significantly at 5, 10, and $20 \mathrm{~g} / \mathrm{kg}$ of AAP group; dietary AAP significantly decreased MDA level at the concentration of $2.5,5,10$ and $20 \mathrm{~g} / \mathrm{kg}$ in contrast with control group on $\mathrm{d} \mathrm{42;5}$ and $20 \mathrm{~g} / \mathrm{kg}$ of AAP increased the gene expression of SOD on d 21, and the gene expression of GSHPx was increased $(\mathrm{P}<0.05)$ in $10 \mathrm{~g} / \mathrm{kg}$ of AAP group on $\mathrm{d} 42$. For the ileum, compared to the control group, 2.5 and $20 \mathrm{~g} / \mathrm{kg}$ of AAP increased SOD activity $(\mathrm{P}<0.05)$; and dietary 10 and $20 \mathrm{~g} / \mathrm{kg}$ of AAP significantly reduced MDA level; dietary $10 \mathrm{~g} / \mathrm{kg}$ of AAP increased the gene expression of SOD, CAT and GSH-Px in broilers on $d$ 42. In conclusion, dietary AAP could improve the antioxidant defenses of liver and small intestine, and the best concentration of the AAP improving hepatic and small intestinal antioxidant status was $20 \mathrm{~g} / \mathrm{kg}$ and $10 \mathrm{~g} / \mathrm{kg}$, respectively.
\end{abstract}

Key words: Artemisia argyi powder, antioxidant, liver, small intestine, broiler

${ }^{\dagger}$ These authors contributed to the work equally and should be regarded as first co-authors.

*This work was supported by National Natural Science Foundation of China under Grant (Project No. 31660674). 
In the animal body, the liver and intestine are the major organs involved in the digestion, absorption, and metabolism of dietary nutrients, and this process can lead to the accumulation of reactive oxygen species (ROS) and free radicals in the intestinal mucosa, liver, and peripheral sites of metabolism (Surai and Fisinin, 2015). In certain concentrations, ROS play important roles in regulating many cellular functions and acting as secondary messengers to activate specific transcription factors (Valko et al., 2007). However, excessive ROS could cause a breakdown of membrane phospholipids and initiate lipid oxidation, probably resulting in a functional alteration of internal organs and leading to widespread damage in broiler chickens (Lambeth, 2004; Liu et al., 2014). To prevent ROS-associated damage, the body has enzymatic and nonenzymatic antioxidant systems. The antioxidative enzymes mainly include catalase (CAT), superoxide dismutase (SOD), and glutathione peroxidase (GSH-Px), and the nonenzymic system includes water-soluble vitamin $\mathrm{C}$, lipid-soluble vitamin E, selenium, copper, and zinc. However, these antioxidant systems are too vulnerable to protect these organs from oxidative damage, when these organs are in oxidative stress (Sun et al., 2009). Therefore, it is important to apply production strategies capable of enhancing the antioxidative function of broilers, and one of these strategies is dietary supplementation with exogenous antioxidants, such as vitamins, minerals, or natural plant extracts with antioxidative ingredients, including polysaccharides, flavonoids, and polyphenols (Delles et al., 2014; Hajati et al., 2014; Surai, 2014). Of these antioxidants, natural plant extracts are attracting interest and becoming major additives in poultry feed, due to their lower toxic effects and various biological activities (Salami et al., 2016).

Artemisia argyi, also known as Chinese mugwort, is a traditional herbal medicine used for treating diseases such as cancer, inflammation, hemostasis and hepatitis (Adams et al., 2006; Cai, 2001; Jeong et al., 2007). Phytochemical and pharmacological studies on this plant have revealed several bioactive chemicals such as polysaccharides, flavonoids, essential oils and triterpenoids, which have been shown to exhibit strong antioxidant and free-radical scavenging activity (Diaz et al., 2012; Huang et al., 2012; Lan et al., 2010; Zhang et al., 2013). Although the above studies have demonstrated the antioxidative activity of Artemisia argyi, the relevant studies were mostly limited to in vitro testing; scant literature is available about the antioxidative activity of Artemisia argyi in the animal body. Recently, our laboratory completed preliminary research evaluating the effect of Artemisia argyi powder (AAP) on broilers, which reported that AAP enhanced the total antioxidant capacity (T-AOC) and reduced the malondialdehyde (MDA) content of broilers (Cao et al., 2015 a). Based on that finding, we carried out further research to determine whether dietary AAP modulates antioxidative status in the small intestine and liver. Therefore, the present study was conducted to examine the T-AOC, the specific activity of antioxidant enzymes such as CAT, SOD, and GSH-Px, and the level of MDA in the small intestine and liver of broilers. Additionally, qRT-PCR analyses were carried out to examine whether the gene expression of the antioxidant enzymes was influenced by AAP. 


\section{Material and methods}

\section{Preparation of AAP}

Artemisia argyi was collected from Hohhot (Inner Mongolia, China) in July; whole plants were sorted, cleaned with distilled water, and dried at ambient temperature $\left(22-25^{\circ} \mathrm{C}\right)$ in the shade. The dried materials were then cut into $1-2 \mathrm{~cm}$ pieces, crushed by a grinder, and sieved through an 80 -mesh sieve to obtain the powder (AAP), which was then stored at ambient temperature $\left(22-25^{\circ} \mathrm{C}\right)$ pending its use.

\section{Analysis of $A A P$}

Before mixing with basal diet, the water extract of Artemisia argyi (WEAA) was prepared to determine the main components and antioxidant capacity in vitro. Total polysaccharide was determined by the phenol-sulfuric acid method using Dglucose as a standard (Saha and Brewer, 1994); the result was expressed as D-glucose equivalents (mg GE/g). Total flavonoid and phenol were measured according to the methods reported previously (Wan et al., 2016); the results were expressed as rutin equivalents ( $\mathrm{mg} \mathrm{RE} / \mathrm{g}$ ) for flavonoid and gallic acid equivalents for phenol (mg $\mathrm{GAE} / \mathrm{g}$ ), respectively. The antioxidant capacities were evaluated by scavenging activities against hydroxyl radical $(\bullet \mathrm{OH})$ and 2, 2-diphenyl-1-picrylhydrazyl (DPPH), as well as ferric reducing antioxidant power (FRAP) test (Shen et al., 2017).

\section{Experimental design, diets, and management}

The experiment was conducted in the experimental farm of Inner Mongolia Agricultural University (Hohhot, China). All animal procedures were performed under the national standard Guideline for Ethical Review of Animal Welfare (GB/T 358922018).

A total of 240 mixed-sex 1-d-old Arbor Acres broilers were distributed according to a single factorial arrangement. All broilers were randomly divided into five treatment groups, each of which consisted of six replicates (one replicate per cage) with eight broilers per replicate. Treatments included one control group (broilers fed with a basal diet) and four AAP groups (broilers fed with a basal diet supplemented with $2.5,5,10$, or $20 \mathrm{~g}$ AAP per $\mathrm{kg}$ feed). The maize- and soybean-based basal diet (Table 1), which was formulated to meet the nutritional requirements of broilers according to the National Research Council (1994) and Agricultural Industry Standards of P.R. China (Feed Standard of Chicken, NY/T 33-2004), was used throughout the $42-\mathrm{d}$ trial, including the starter (d 1-21) and grower (d 22-42) periods. During the experimental period, broilers were housed in metal cages $(0.8 \mathrm{~m} \times 0.8 \mathrm{~m} \times 0.5 \mathrm{~m})$. Infrared heating devices were installed in the chicken house to maintain the temperature automatically. The temperature was set at $33^{\circ} \mathrm{C}$ for the first $3 \mathrm{~d}$ and then gradually reduced at a rate of $3^{\circ} \mathrm{C}$ per week to a final temperature of $21^{\circ} \mathrm{C}$. The lighting regime was $23 \mathrm{~h} \mathrm{light} / 1 \mathrm{~h}$ dark for the first three days, followed by $18 \mathrm{~h}$ light $/ 6 \mathrm{~h}$ dark for the rest of the trial period. Feed and water were provided ad libitum throughout the experiment. The vaccination program was made as follows: 


\begin{tabular}{lll}
\hline \multicolumn{1}{c|}{ Age of broilers } & \multicolumn{1}{c}{ Vaccine name } & \multicolumn{1}{c}{ Inoculation mode } \\
\hline 3-day-old & $\begin{array}{l}\text { Newcastle disease and infectious bronchitis } \\
\text { 20-day-old }\end{array}$ & Eye drops and nose drops \\
13-day-old & Medium-virulence strains of infectious bursal & Drinking water \\
24-day-old & live vaccine & \\
16-day-old & Avian influenza vaccine & Intramuscular injection \\
\hline
\end{tabular}

Table 1. Composition and nutrient levels of basal diet (calculated on air-dry basis, \%)

\begin{tabular}{lcc}
\hline \multicolumn{1}{c|}{ Ingredient } & $\mathrm{d} 1-21$ & $\mathrm{~d} 22-42$ \\
\hline Corn & 51.68 & 58.49 \\
Soybean meal & 41.00 & 34.30 \\
Soybean oil & 3.00 & 3.00 \\
Dicalcium phosphate & 1.90 & 1.80 \\
Limestone & 1.10 & 1.20 \\
Salt & 0.37 & 0.37 \\
Lysine (98\%) & 0.05 & 0.03 \\
Methionine & 0.19 & 0.10 \\
Premix ${ }^{1}$ & 0.71 & 0.71 \\
Total & 100 & 100 \\
Nutrient levels & & \\
Crude protein & & 19.95 \\
ME (MJ/kg) & 21.84 & 12.87 \\
Calcium & 12.62 & 1.00 \\
Available phosphorus & 1.00 & 0.46 \\
Lysine & 0.48 & 1.20 \\
Methionine & 1.40 & 0.44 \\
L-cystine & 0.56 & 0.37 \\
\hline
\end{tabular}

${ }^{1}$ Composition of premix (per kg of feed): vitamin $\mathrm{A}-6141.5 \mathrm{IU}$; vitamin $\mathrm{D}_{3}-1789.2 \mathrm{IU}$; vitamin $\mathrm{E}-7.99$ mg; vitamin $\mathrm{K}-1.82 \mathrm{mg}$; vitamin $\mathrm{B}_{1}-0.65 \mathrm{mg}$; vitamin $\mathrm{B}_{2}-3.93 \mathrm{mg}$; vitamin $\mathrm{B}_{6}-2.08 \mathrm{mg}$; vitamin $\mathrm{B}_{12}-0.01$ $\mathrm{mg}$; niacin $-18.06 \mathrm{mg}$; calcium pantothenate $-6.65 \mathrm{mg}$; folic acid $-0.59 \mathrm{mg}$; biotin $-0.07 \mathrm{mg}$; choline chloride $-332.28 \mathrm{mg} ; \mathrm{Fe}-60.91 \mathrm{mg} ; \mathrm{Cu}-6.01 \mathrm{mg}$; Zn $-65.75 \mathrm{mg}$; Mn - 62.3 mg; I-0.9 mg; Se - $0.21 \mathrm{mg}$.

${ }^{2}$ Crude protein was measured value, while others were calculated values.

\section{Sampling and measurements}

\section{Collection of liver and small intestine}

On d 21 and 42, 12 broilers per treatment ( 2 broilers per replicate) were randomly selected and euthanized by cervical dislocation. Each broiler's liver was collected and placed in a cryogenic vial after being washed with ice-cold sterile saline solution to remove blood contamination. The small intestine was dissected, and a 7-cm intestinal segment was collected from the distal duodenum, mid-jejunum, and midileum. The intestinal segments were opened longitudinally, and the contents were rinsed gently with sterile saline and then placed in cryogenic vials. All samples were stored at $-80^{\circ} \mathrm{C}$ until analysis of antioxidative indexes and relative gene expression. 


\section{Preparation of the tissue homogenates}

About $0.5 \mathrm{~g}$ of liver or small intestine was used to prepare the homogenate. The minced tissue was homogenized in an ice-cold $0.9 \%$ sodium chloride solution $(\mathrm{w} / \mathrm{v}$, 1:9) using a glass homogenate tube and then centrifuged at $1346 \times \mathrm{g}$ for $10 \mathrm{~min}$ at room temperature, and the supernatant was collected and stored at $-80^{\circ} \mathrm{C}$ until further analysis.

\section{Biochemical assay determination of liver and small intestine}

The T-AOC, SOD, CAT, and GSH-Px activities and MDA content in both the liver and the small intestine were determined spectrophotometrically using a commercial kit purchased from Nanjing Jiancheng Bioengineering Institute (Nanjing, Jiangsu, China), according to the manufacturer's instructions. Briefly, T-AOC activity was measured using the ferric reducing/antioxidant power assay described by Benzie and Strain (1999), and the change in absorbance was detected at $520 \mathrm{~nm}$; SOD activity was measured by the xanthine and xanthine oxidase/cytochrome $c$ method (McCord and Fridovich, 1969), and the change in absorbance was detected at $550 \mathrm{~nm}$; CAT activity was measured by the rate of $\mathrm{H}_{2} \mathrm{O}_{2}$ disappearance according to the method of Aebi (1984), and the change in absorbance was detected at $405 \mathrm{~nm}$; GSH-Px activity was determined at an absorbance of $412 \mathrm{~nm}$ with the dithio-nitro benzene method described by Hafeman et al. (1974); and the concentration of MDA was assayed by measuring TBA-reactive substances with a spectrophotometer at 532 $\mathrm{nm}$, as described by Placer et al. (1966). The activities of T-AOC, SOD, CAT, and GSH-Px in tissue homogenates were expressed as U per milligram of protein; the tissue homogenate MDA content was expressed as nanomoles per milligram of protein. The protein concentrations of the tissue homogenates were determined by using the bicinchoninic acid assay (Walker, 2009).

\section{Quantitative real-time PCR}

The mRNA levels of the antioxidative enzymes (SOD, CAT, and GSH-Px) in the liver and small intestine were determined by the SYBR Green II chimeric fluorescence method (Zhang et al., 2014). Total RNA was extracted from tissue samples using the RNAiso Plus kit (TaKaRa Biotechnology, Dalian, China) according to the manufacturer's protocol. The RNA integrity was checked using agarose gel electrophoresis with ethidium bromide staining. The RNA concentration and purity were determined using an automatic microplate reader (Synergy H4, BioTek, Tokyo, Japan) at an OD 260/280 reading (ratio 1.8-2.1). After determining the RNA concentration, $1 \mu \mathrm{g}$ of total RNA was reverse-transcribed into complementary DNA (cDNA) using the PrimeScript RT Reagent Kit with gDNA Eraser (TaKaRa Biotechnology). Real-time PCR was performed with an ABI StepOnePlus Real-Time PCR system (Applied Biosystems, Grand Island, NY) using the SYBR Premix Ex Taq II Reagent Kit (TaKaRa Biotechnology), according to the manufacturer's instructions with a modification (Zhang et al., 2018). Briefly, the volume of the reaction system is $20 \mu \mathrm{L}$, including $10 \mu \mathrm{L}$ of SYBR Premix Ex Taq $\Pi, 0.4 \mu \mathrm{L}$ of PCR forward primer $(10 \mu \mathrm{M}), 0.4 \mu \mathrm{L}$ of PCR reverse primer $(10 \mu \mathrm{M}), 2 \mu \mathrm{L}$ of cDNA, and $7.2 \mu \mathrm{L}$ of RNase-free $\mathrm{H}_{2} \mathrm{O}$. The PCR reaction procedure was as follows: a pre-run at $95^{\circ} \mathrm{C}$ for 
$30 \mathrm{~s}$ and 40 cycles of denaturation at $95^{\circ} \mathrm{C}$ for $5 \mathrm{~s}$, followed by an annealing step for $30 \mathrm{~s}$ (different annealing temperatures for different target genes). The melting curve program was as follows: one cycle of denaturation at $95^{\circ} \mathrm{C}$ for $10 \mathrm{~s}$, followed by an increase in temperature from 70 to $95^{\circ} \mathrm{C}$ at a rate of $0.5^{\circ} \mathrm{C} / \mathrm{s}$. The primer sequences of the target and reference genes (SOD, CAT, GSH-Px, and $\beta$-Actin), obtained from GenBank, are shown in Table 2. The relative levels of mRNA expression were calculated using the $2^{-\triangle \Delta C T}$ method after normalization against the reference gene $\beta$-Actin (Livak and Schmittgen, 2001).

Table 2. Genes and their primer sequences

\begin{tabular}{|c|c|c|c|}
\hline Gene name ${ }^{1}$ & Gene number & Primer sequence $^{2}$ & Fragment size \\
\hline \multirow[t]{2}{*}{$\beta$-Actin } & NM_205518 & F-GCCAACAGAGAGAAGATGACAC & $140 \mathrm{bp}$ \\
\hline & & R-GTAACACCATCACCAGAGTCCA & \\
\hline \multirow[t]{2}{*}{ SOD } & NM_205064.1 & F-TTGTCTGATGGAGATCATGGCTTC & $98 \mathrm{bp}$ \\
\hline & & R-TGCTTGCCTTCAGGATTAAAGTGA & \\
\hline \multirow[t]{2}{*}{ CAT } & NM_001031215.1 & F-GTTGGCGGTAGCAGTCTGGTCT & $182 \mathrm{bp}$ \\
\hline & & R-GTGGTCAAGGCATCTGGCTTCTG & \\
\hline \multirow[t]{2}{*}{ GSH-Px } & NM_001163245.1 & F-CAAAGTTGCGGTCAGTGGA & $136 \mathrm{bp}$ \\
\hline & & R-AGAGTCCCAGGCCTTTACTACTTTC & \\
\hline
\end{tabular}

${ }^{\mathrm{I}} \mathrm{CAT}=$ catalase; $\mathrm{SOD}=$ superoxide dismutase $\mathrm{GSH}-\mathrm{Px}=$ glutathione peroxidase.

${ }^{2} \mathrm{~F}=$ forward primer; $\mathrm{R}=$ reverse primer.

\section{Statistical analysis}

All data were analyzed using SAS 9.0 software (SAS, 2003) to determine the statistical significance of the treatment groups. Results were expressed as treatment means and SEM. Compatibility of characteristics distribution with normal distribution was examined with Shapiro-Wilk's test. Orthogonal comparison was used to evaluate the linear and quadratic effects of AAP on the various antioxidative responses, and the significant levels were expressed with P-value. In addition, Duncan's multiple comparisons test was used to identify the significant difference between treatment groups, and the significant level was differentiated with different letters $(\mathrm{a}, \mathrm{b})$. A probability level of $\mathrm{P}<0.05$ was chosen as the limit for statistical significance.

\section{Results}

\section{Main content and antioxidant activities (in vitro) of AAP}

The extraction rate of WEAA (Table 3) was $73.9 \pm 0.20 \mathrm{mg}$ per g of Artemisia argyi powder. The contents of total polysaccharide, flavonoid and phenol in WEAA were $93.8 \pm 0.31 \mathrm{mg}$ GE per $\mathrm{g}, 109.7 \pm 0.92 \mathrm{mg}$ RE per $\mathrm{g}$ and $51.0 \pm 0.13 \mathrm{mg}$ GAE per g, respectively. The scavenging activity of WEAA against $\bullet \mathrm{OH}$ and DPPH were $34.99 \pm 1.11 \%$ and $74.12 \pm 0.50 \%$, respectively; the ferric reducing power was $2.58 \pm 0.03 \%$. 


\section{The hepatic antioxidant status}

As shown in Table 4, on $\mathrm{d} 42$, the hepatic T-AOC was improved linearly $(\mathrm{P}=0.01)$ or quadratically $(\mathrm{P}=0.04)$ with the increase of AAP supplementation, and the greatest level was observed in the $20 \mathrm{~g} / \mathrm{kg}$ AAP group which was significantly increased compared with the control group $(\mathrm{P}<0.05)$. Adding $20 \mathrm{~g} / \mathrm{kg}$ AAP in diet increased the hepatic CAT activity of broilers on $\mathrm{d} 21(\mathrm{P}<0.05)$, and the CAT activity was elevated linearly $(\mathrm{P}=0.02$ on $\mathrm{d} 21$ and $\mathrm{P}=0.01$ on $\mathrm{d} 42)$ or quadratically $(\mathrm{P}=0.04$ on $\mathrm{d} 42$ ) by the inclusion of AAP. In addition, on $\mathrm{d} 21$, diets supplemented with 5,10 , $20 \mathrm{~g} / \mathrm{kg}$ of AAP significantly enhanced the hepatic GSH-Px activity compared with the control diet, and the GSH-Px activity showed a quadratic dose-dependent effect $(\mathrm{P}=0.02)$. In contrast with control group, dietary $20 \mathrm{~g} / \mathrm{kg}$ AAP significantly reduced the hepatic MDA level on d 42, and the MDA level showed the linear or quadratic dose-dependent effect $(\mathrm{P}=0.04)$.

Table 3. Main chemical components and antioxidant activity of water extract of Artemisia argyi (WEAA)

\begin{tabular}{|c|c|}
\hline Items & Results \\
\hline Extraction rate of $\mathrm{WEAA}^{1}$ & $73.9 \pm 0.20$ \\
\hline Total polysaccharide (mg GE/g) & $93.8 \pm 0.31$ \\
\hline Total flavonoid (mg RE/g) & $109.7 \pm 0.92$ \\
\hline Total phenol (mg GAE/g) & $51.0 \pm 0.13$ \\
\hline Ferric reducing power $(\%)$ & $2.58 \pm 0.03$ \\
\hline -OH scavenging power ${ }^{2}(\%)$ & $34.99 \pm 1.11$ \\
\hline DPPH clearance rate ${ }^{3}(\%)$ & $74.12 \pm 0.50$ \\
\hline
\end{tabular}

${ }^{\dagger}$ Each value is expressed as mean \pm SD $(n=3)$.

${ }^{1}$ Extraction rate $=$ Weight of AAE dry powder / weight of Artemisia argyi plant powder $(\mathrm{mg} / \mathrm{g})$.

$2 \cdot \mathrm{OH}$, Hydroxyl radical.

${ }^{3} \mathrm{DPPH}, 2$, 2-diphenyl-1-picrylhydrazyl.

Table 4. Effect of AAP on hepatic antioxidant of broilers

\begin{tabular}{|c|c|c|c|c|c|c|c|c|c|}
\hline \multirow{2}{*}{ Items $^{1}$} & \multicolumn{5}{|c|}{ AAP supplemental level (g/kg) } & \multirow{2}{*}{$\mathrm{SEM}^{2}$} & \multicolumn{3}{|c|}{ P-value ${ }^{3}$} \\
\hline & 0 & 2.5 & 5 & 10 & 20 & & $\mathrm{P}$ & Lin-P & Quad-P \\
\hline 1 & 2 & 3 & 4 & 5 & 6 & 7 & 8 & 9 & 10 \\
\hline \multicolumn{10}{|l|}{ T-AOC } \\
\hline $21 \mathrm{~d}$ & 1.26 & 1.45 & 1.86 & 1.58 & 1.69 & 0.18 & 0.38 & 0.37 & 0.41 \\
\hline $42 \mathrm{~d}$ & $1.22 \mathrm{~b}$ & $1.54 \mathrm{ab}$ & $1.47 \mathrm{ab}$ & $1.55 \mathrm{ab}$ & $1.89 \mathrm{a}$ & 0.15 & 0.13 & 0.01 & 0.04 \\
\hline \multicolumn{10}{|l|}{ SOD } \\
\hline $21 \mathrm{~d}$ & 169.72 & 241.47 & 295.64 & 220.95 & 229.85 & 24.79 & 0.23 & 0.97 & 0.73 \\
\hline $42 \mathrm{~d}$ & 226.94 & 227.14 & 215.06 & 240.08 & 275.89 & 23.45 & 0.79 & 0.21 & 0.43 \\
\hline \multicolumn{10}{|l|}{ CAT } \\
\hline $21 \mathrm{~d}$ & $18.58 \mathrm{~b}$ & $22.20 \mathrm{ab}$ & $26.38 \mathrm{ab}$ & $26.82 \mathrm{ab}$ & $38.57 \mathrm{a}$ & 5.12 & 0.23 & 0.02 & 0.06 \\
\hline $42 \mathrm{~d}$ & 34.03 & 31.12 & 31.14 & 39.19 & 41.95 & 3.04 & 0.08 & 0.01 & 0.04 \\
\hline
\end{tabular}


Table 4 - contd.

\begin{tabular}{l|c|c|c|c|c|c|c|c|c}
\hline \multicolumn{1}{c|}{1} & \multicolumn{1}{c|}{2} & 3 & 4 & 5 & 6 & 7 & 8 & 9 & 10 \\
\hline GSH-Px \\
$21 \mathrm{~d}$ & $13.20 \mathrm{~b}$ & $17.17 \mathrm{~b}$ & $47.90 \mathrm{a}$ & $38.12 \mathrm{a}$ & $35.23 \mathrm{a}$ & 5.89 & $<0.01$ & 0.15 & 0.02 \\
$42 \mathrm{~d}$ & 24.78 & 26.63 & 22.23 & 34.07 & 28.17 & 2.95 & 0.08 & 0.23 & 0.27 \\
$\mathrm{MDA}$ & & & & & & & & & \\
$21 \mathrm{~d}$ & 0.72 & 0.62 & 0.57 & 0.40 & 0.45 & 0.11 & 0.60 & 0.15 & 0.23 \\
$42 \mathrm{~d}$ & $1.97 \mathrm{a}$ & $1.69 \mathrm{ab}$ & $1.48 \mathrm{ab}$ & $1.42 \mathrm{ab}$ & $1.22 \mathrm{~b}$ & 0.19 & 0.18 & 0.02 & 0.04 \\
\hline
\end{tabular}

$\mathrm{a}, \mathrm{b}-$ within the same row, different letters indicate significant differences between groups $(\mathrm{P}<0.05)$.

${ }^{1} \mathrm{AAP}=$ Artemisia argyi powder; T-AOC $(\mathrm{U} / \mathrm{mgprot})=$ total antioxidant capacity; $\mathrm{SOD}(\mathrm{U} / \mathrm{mgprot})=$ super dismutase; CAT $(\mathrm{U} / \mathrm{mgprot})=$ catalase; GSH-Px $(\mathrm{U} / \mathrm{mgprot})=$ glutathione peroxidase; MDA $(\mathrm{nmol} / \mathrm{mgprot})=$ malondialdehyde.

${ }^{2} \mathrm{SEM}=$ standard error of the mean.

${ }^{3} \mathrm{P}$ represents the differences between five treatment groups analyzed by one-way ANOVA; Lin-P and Quad-P represent the dose-dependent effect of AAP tested by orthogonal comparisons.

The hepatic gene expressions of antioxidative enzymes are shown in Figure 1. Compared with control group, diet supplemented with $10 \mathrm{~g} / \mathrm{kg}$ of AAP significantly increased the gene expression of SOD and CAT on $\mathrm{d} 42$.

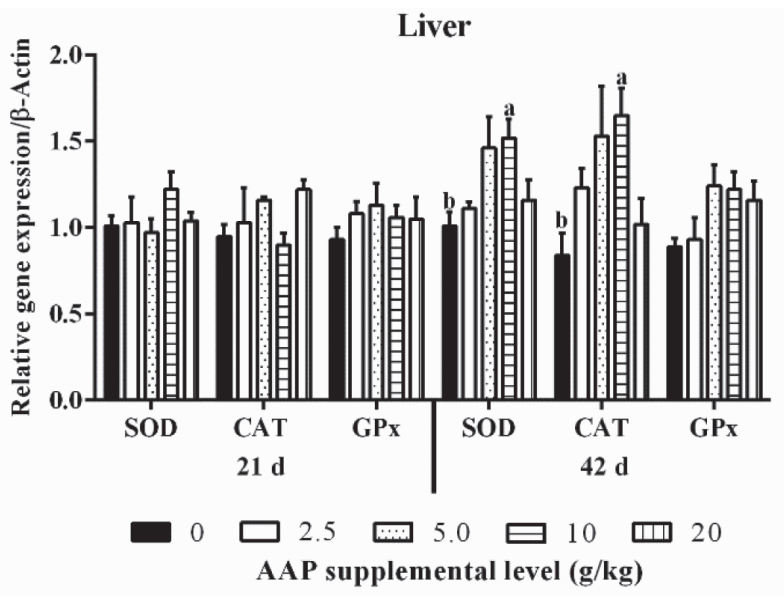

Figure 1. Effect of dietary AAP on the relative gene expression of CAT, SOD and GSH-Px in the liver of broilers. Results are presented as mean $\pm \mathrm{SD}(n=6)$. Each bar carrying different letters $(\mathrm{a}, \mathrm{b})$ was significantly different $(\mathrm{P}<0.05)$

\section{The small intestinal antioxidant status}

\section{Duodenum}

With the increase in dietary AAP, SOD activity was enhanced quadratically in the duodenum ( $\mathrm{P}=0.03)$ on $\mathrm{d} 21$ (Table 5). In addition, compared to the control group, $10 \mathrm{~g} / \mathrm{kg}$ of AAP increased the duodenal SOD activity on d $21(\mathrm{P}<0.05)$; the gene expression was increased both on $\mathrm{d} 21$ and on $\mathrm{d} 42$ (Figure $2 \mathrm{~A}$ ). Diet supplemented with $10 \mathrm{~g} / \mathrm{kg}$ of AAP reduced the duodenal MDA level of broilers on $\mathrm{d} 21(\mathrm{P}<0.05)$; 
the dose-dependent effect analysis showed that diet with AAP quadratically reduced the MDA content in the duodenum $(\mathrm{P}=0.03)$. Although the increased CAT activity was not observed, the gene expression was increased in the $20 \mathrm{~g} / \mathrm{kg}$ of AAP treatment compared with the control group on $\mathrm{d} 42(\mathrm{P}<0.05$, Figure $2 \mathrm{~A})$.

Table 5. Effect of AAP on small intestinal antioxidant of broilers

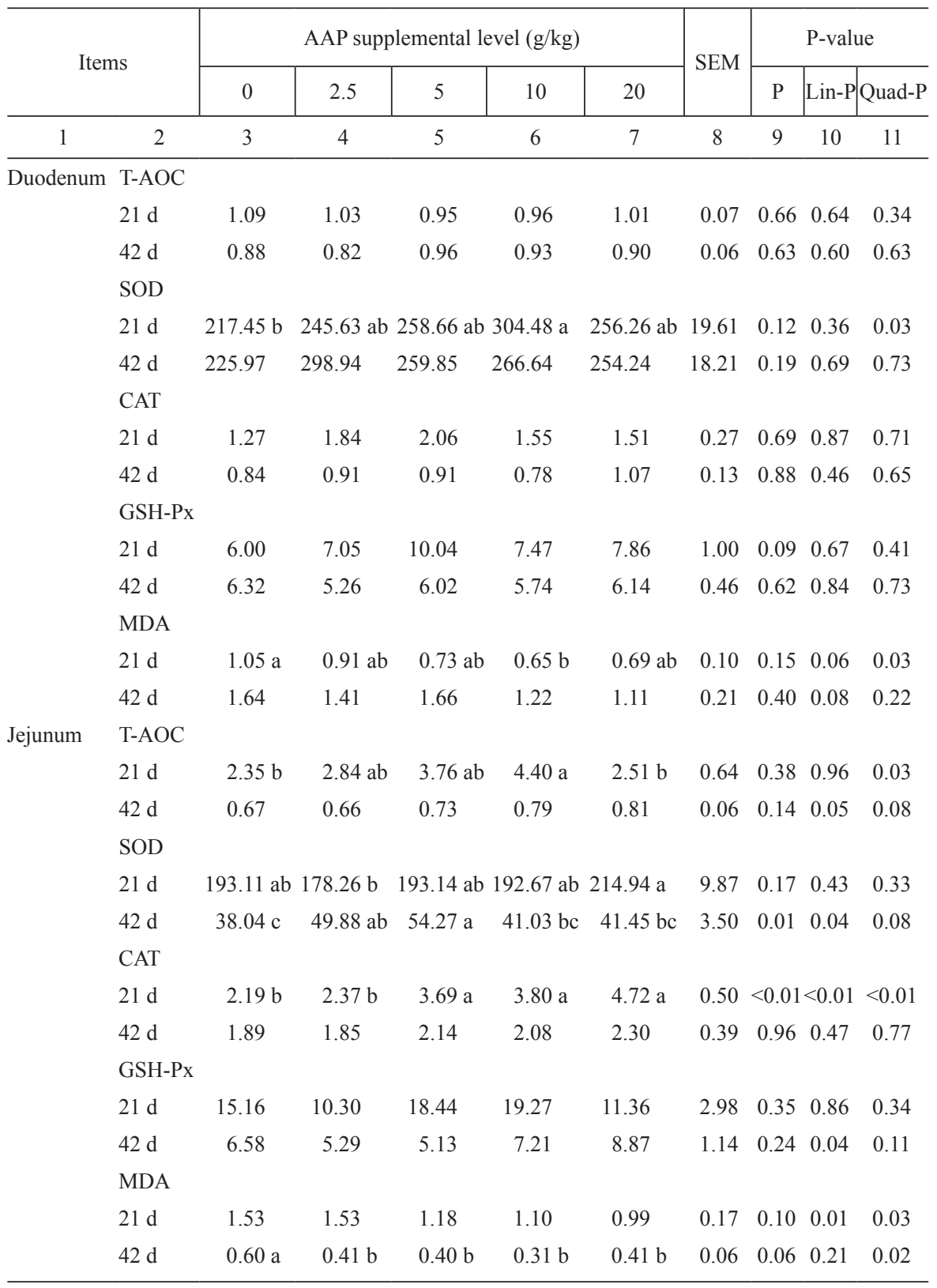


Table 5 - contd.

\begin{tabular}{|c|c|c|c|c|c|c|c|c|c|c|}
\hline 1 & 2 & 3 & 4 & 5 & 6 & 7 & 8 & 9 & 10 & 11 \\
\hline \multirow[t]{15}{*}{ Ileum } & \multicolumn{10}{|c|}{ T-AOC } \\
\hline & $21 \mathrm{~d}$ & 2.92 & 2.27 & 3.32 & 2.96 & 2.25 & 0.33 & 0.11 & 0.43 & 0.30 \\
\hline & $42 \mathrm{~d}$ & 0.92 & 1.16 & 1.03 & 1.19 & 1.03 & 0.12 & 0.59 & 0.81 & 0.46 \\
\hline & \multicolumn{10}{|l|}{ SOD } \\
\hline & $21 \mathrm{~d}$ & 70.55 & 73.81 & 78.49 & 85.10 & 79.81 & 6.98 & 0.76 & 0.35 & 0.38 \\
\hline & $42 \mathrm{~d}$ & $173.65 \mathrm{c}$ & $219.94 a b$ & $190.39 \mathrm{c}$ & $196.09 \mathrm{bc}$ & $226.33 \mathrm{a}$ & 10.56 & 0.01 & 0.03 & 0.09 \\
\hline & \multicolumn{10}{|l|}{ CAT } \\
\hline & $21 \mathrm{~d}$ & 1.49 & 1.51 & 2.04 & 2.09 & 2.26 & 0.22 & 0.12 & 0.02 & 0.04 \\
\hline & $42 \mathrm{~d}$ & 2.63 & 2.47 & 2.20 & 2.07 & 2.63 & 0.26 & 0.73 & 0.86 & 0.34 \\
\hline & \multicolumn{10}{|c|}{ GSH-Px } \\
\hline & $21 \mathrm{~d}$ & 11.73 & 17.36 & 17.70 & 17.26 & 17.24 & 2.37 & 0.57 & 0.43 & 0.41 \\
\hline & $42 \mathrm{~d}$ & 14.15 & 18.95 & 18.11 & 15.97 & 14.45 & 1.40 & 0.22 & 0.34 & 0.29 \\
\hline & \multicolumn{10}{|l|}{ MDA } \\
\hline & $21 \mathrm{~d}$ & 1.40 & 1.31 & 1.35 & 1.28 & 1.36 & 0.18 & 0.99 & 0.97 & 0.94 \\
\hline & $42 \mathrm{~d}$ & $0.79 \mathrm{a}$ & $0.74 \mathrm{a}$ & $0.58 \mathrm{ab}$ & $0.46 \mathrm{~b}$ & $0.44 \mathrm{~b}$ & 0.09 & 0.04 & 0.01 & 0.01 \\
\hline
\end{tabular}

$\mathrm{a}, \mathrm{b}$ - within the same row, different letters indicate significant differences between groups $(\mathrm{P}<0.05)$.

${ }^{1} \mathrm{AAP}=$ Artemisia argyi powder; T-AOC $(\mathrm{U} / \mathrm{mgprot})=$ total antioxidant capacity; SOD $(\mathrm{U} / \mathrm{mgprot})=$ super dismutase; $\mathrm{CAT}=$ catalase; $\mathrm{GSH}-\mathrm{Px}(\mathrm{U} / \mathrm{mgprot})=$ glutathione peroxidase; $\mathrm{MDA}(\mathrm{nmol} / \mathrm{mgprot})=$ malondialdehyde.

${ }^{2} \mathrm{SEM}=$ standard error of the mean.

${ }^{3} \mathrm{P}$ represents the differences between five treatment groups analyzed by one-way ANOVA; Lin-P (linear) and Quad-P (quadratic) represent the dose-dependent effect of AAP tested by orthogonal comparisons.
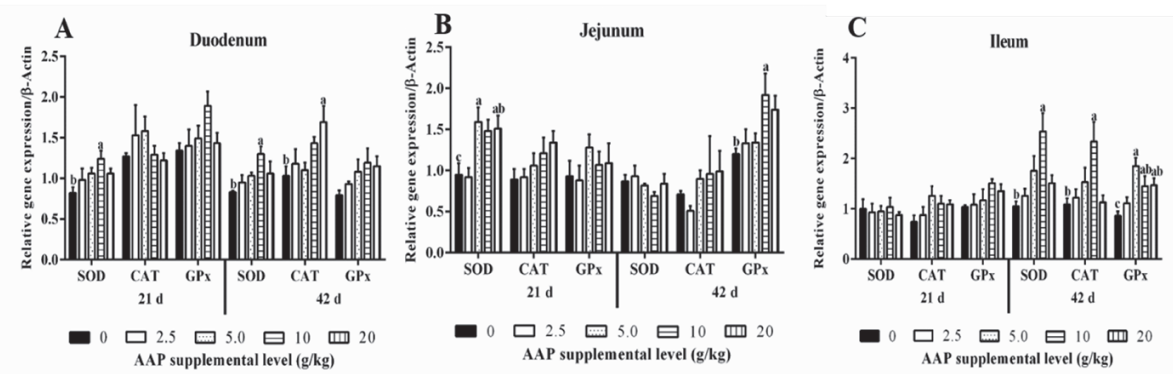

Figure 2. Effect of dietary AAP on the relative gene expression of CAT, SOD and GSH-Px in the small intestine of broilers. (A) The gene expression in duodenum; (B) The gene expression in jejunum; (C) The gene expression in ileum. Results are presented as mean $\pm \mathrm{SD}(n=6)$. Each bar carrying different letters (a, b) was significantly different $(\mathrm{P}<0.05)$ 


\section{Jejunum}

As shown in Table 5, on d 21, compared with the control group, the diet with AAP quadratically increased the T-AOC of broilers $(\mathrm{P}=0.03)$, and the greatest level was observed in the $10 \mathrm{~g} / \mathrm{kg}$ AAP group $(\mathrm{P}<0.05)$. The SOD activity was linearly increased $(\mathrm{P}=0.04)$ with the increase of AAP on $\mathrm{d} 42$, but the significant differences were not found as compared to the control group. Surprisingly, the gene expression of SOD was increased by 5 and $20 \mathrm{~g} / \mathrm{kg}$ of AAP on d 21 ( $\mathrm{P}<0.05$; Figure $2 \mathrm{~B})$, but not on $\mathrm{d} 42$. In terms of the CAT activity, compared with the control group, the significant differences were observed in 5,10 , and $20 \mathrm{~g} / \mathrm{kg}$ of AAP groups. The inclusion of AAP linearly or quadratically elevated CAT activity on d $21(\mathrm{P}<0.01)$. On d 42, GSH-Px activity in the jejunum was linearly increased $(\mathrm{P}=0.04)$ by the inclusion of AAP; the gene expression of GSH-Px was increased ( $\mathrm{P}<0.05$; Figure $2 \mathrm{~B}$ ) in $10 \mathrm{~g} / \mathrm{kg}$ of AAP treatment group, but there was no significant difference for GSH-Px activity between the treatment groups. MDA level was decreased linearly $(\mathrm{P}=0.01$ on $\mathrm{d} 21)$ or quadratically ( $\mathrm{P}=0.03$ on $\mathrm{d} 21 ; \mathrm{P}=0.02$ on $\mathrm{d} 42)$ with the increase of AAP supplementation. Dietary AAP significantly decreased MDA level at the concentration of $2.5,5,10$ and $20 \mathrm{~g} / \mathrm{kg}$ on $\mathrm{d} 42$.

\section{Ileum}

With the increase in dietary AAP, the SOD activity in ileum was enhanced linearly $(\mathrm{P}=0.03$ ) on $\mathrm{d} 42$ (Table 5). In addition, compared to the control group, 2.5 and $20 \mathrm{~g} / \mathrm{kg}$ of AAP increased the ileal SOD activity $(\mathrm{P}<0.05)$. The inclusion of AAP linearly $(\mathrm{P}=0.02)$ or quadratically $(\mathrm{P}=0.04)$ elevated CAT activity on $\mathrm{d} 21$. Diets with AAP reduced MDA content linearly $(\mathrm{P}=0.01)$ or quadratically $(\mathrm{P}=0.01)$ on $\mathrm{d}$ 42, and dietary 10 and $20 \mathrm{~g} / \mathrm{kg}$ of AAP significantly reduced MDA level compared with the control diet. As for the gene expression (Figure $2 \mathrm{C}$ ), diet with $10 \mathrm{~g} / \mathrm{kg}$ of AAP increased the gene expression of SOD, CAT and GSH-Px in broilers on $\mathrm{d} 42$ $(\mathrm{P}<0.05)$. In addition, GSH-Px gene expression was also increased by inclusion of 5 and $20 \mathrm{~g} / \mathrm{kg}$ AAP.

\section{Discussion}

In living animals, the balance between antioxidants and pro-oxidants (redox homeostasis) is an important physiological process, and dietary antioxidants can help maintain this balance in the animal body (Surai and Fisinin, 2015). The analysis of bioactive components in the current study have identified the content of polysaccharides, flavonoids, phenols existing in AAP; the antioxidative effects (in vitro) also were proved, which is similar to the results of previous reports (Cai et al., 2004; Lan et al., 2010; Lv et al., 2013). As the main component in AAP was total flavonoid (109.7 $\pm 0.92 \mathrm{mg}$ rutin equivalents), it is reasonable to speculate that AAP may have the same antioxidant effect as rutin, and can be used as feed additive of chickens (Awad et al., 2019; Hassan et al., 2019). Cao et al. (2015 a) found that dietary AAP could increase the serum T-AOC and reduce the serum MDA content of broilers, 
which suggested that AAP also exerts its antioxidative effect in animal body. In addition, the previous study demonstrated that $2.5 \mathrm{~g} / \mathrm{kg}$ of AAP is the best concentration to increase average daily weight gain of broilers during the grower period, and $5 \mathrm{~g} / \mathrm{kg}$ of AAP is the optimal dose to improve feed utilization (Cao et al., $2015 \mathrm{~b}$ ). Thus, the improved growth performance induced by AAP may partly relate to its antioxidant effect on broilers. As the AAP can be absorbed and digested with the diet by the small intestine and liver, we may speculate that AAP also can improve the antioxidant of small intestine and liver.

A recent study demonstrated that the oxidation-reduction process started in the intestine (Surai and Fisinin, 2015). The dietary nutrients absorbed into the small intestine contain plenty of antioxidants but also a range of potential pro-oxidants, and consumption of pro-oxidants may cause oxidative damage to the intestine. It is therefore important to enhance antioxidative capacity in the small intestine. In the present study, dietary AAP enhanced SOD activity in the duodenum alone, whereas jejunal SOD, CAT, and GSH-Px activities were all improved by AAP, and increased SOD and CAT activities were also observed in the ileum, similar to a previous study by Zhao et al. (2016), who reported that dietary Artemisia argyi aqueous extract enhanced intestinal antioxidative enzyme activities. In addition, increased relative gene expressions were also observed in the small intestine, but this may partially explain the increased antioxidative enzyme activities, because the variation in relative gene expression was not totally in line with the variation in the enzymatic activities. This was probably because the enzymatic activity was affected by various factors, not just gene expression (Halliwell and Gutteridge, 2015). MDA level in the small intestine was reduced by dietary AAP, which suggested that dietary Artemisia argyi could protect the small intestine from damage caused by lipid peroxidation and help maintain redox homeostasis. This benefit might be due to the improved enzymatic activities, or might be attributed to the high antioxidant content of Artemisia argyi (Cai et al., 2004; Diaz et al., 2012). Although we observed increased enzyme activity and a compromised MDA level in the small intestine of broilers fed with AAP diets, the increased T-AOC level was observed in the jejunum only, which suggested that AAP had strong effect on antioxidative capacity in the jejunum. Taking all these results together, it is reasonable to assume that dietary Artemisia argyi could exert a beneficial effect on antioxidative capacity by enhancing enzymatic activity and directly scavenging the hydroxide radical and superoxide anion radical in small intestine, and then could potentially help maintain redox homeostasis.

The liver is the primary detoxifying organ in animal body, and has a high metabolic rate of nutrients from dietary feed. The potential antioxidants (polysaccharides, flavonoids, phenols) in AAP will reach the liver via the portal vein after absorption along the gastrointestinal tract. Therefore, the potential beneficial effect of antioxidants would take place primarily in liver. In the present study, no improvement of hepatic SOD activity was observed, even though the corresponding mRNA was increased on $\mathrm{d} 42$. This may be because the superoxide anion radical in the liver was directly removed by the potential antioxidants in AAP, not by enhancing SOD activity (Huang et al., 2012). We observed that CAT activity was enhanced throughout the entire experiment, whereas GSH-Px activity was promoted only on $\mathrm{d} 21$. This 
suggests that AAP may possess the ability to eliminate $\mathrm{H}_{2} \mathrm{O}_{2}$ by enhancing CAT or GSH-Px activity, and the enhancing effect on CAT is stronger. Such observations can be explained by the fact that CAT is primarily concentrated in the liver (Halliwell and Gutteridge, 2015). In addition, the increased CAT gene expression on d 42 partially supports this finding, but the increasing tendency of GSH-Px gene expression does not make sense. The increased antioxidative enzyme activity observed in our study would lead to a decrease in the formation of lipid peroxidation products such as MDA, and the compromised MDA level observed on d 42 could be good evidence. We also found that the hepatic T-AOC of broilers was improved by AAP supplementation on $\mathrm{d} 42$, which indicated that AAP showed a certain degree of antioxidative ability, and this was at least partly due to the enhanced activity of CAT and GSH-Px, or the compromised MDA level.

\section{Conclusion}

In summary, the present study provided some evidence that AAP supplementation improved antioxidative status in the liver and small intestine of broilers by elevating antioxidative enzyme activity and reducing lipid peroxidative products. Furthermore, AAP increased antioxidative enzyme activity, at least in part, by upregulating the gene expression of antioxidative enzymes in the liver and small intestine. In addition, the best concentration of AAP improving hepatic and small intestinal antioxidant status was $20 \mathrm{~g} / \mathrm{kg}$ and $10 \mathrm{~g} / \mathrm{kg}$, respectively.

\section{Conflict of interest statement}

The authors declare that there are no conflicts of interest.

\section{Acknowledgments}

The authors would like to express gratitude to the colleagues in the Laboratory of Animal Production, College of Animal Science for their assistance in sample collection, data and laboratory analysis.

\section{References}

A d a m s M., Efferth T., B a u e r R. (2006). Activity-guided isolation of scopoletin and isoscopoletin, the inhibitory active principles towards CCRF-CEM leukaemia cells and multi-drug resistant CEM/ADR5000 cells, from Artemisia argyi. Planta Med., 72: 862-864.

A e b i H. (1984). Catalase in vitro. Method. Enzymol., 105: 121-126.

Aw a d A., Z a g l o o 1 A.W., K h a 1 il S.R. (2019). Immunohaematological status and mRNA expression of the genes encoding interleukin- 6 , nuclear-factor kappa B, and tumor-necrosis factor- $\alpha$ in the spleen of broilers supplemented with dietary rutin. Anim Prod. Sci., 59: 1454-1461.

B en zi e I.F., Strain J. (1999). Ferric reducing/antioxidant power assay: Direct measure of total antioxidant activity of biological fluids and modified version for simultaneous measurement of total antioxidant power and ascorbic acid concentration. Method. Enzymol., 299: 15-27.

C a i P. (2001). The pharmacological action and application of Artemisia argyi. Lishizhen Med. Mat. Med. Res., 12: 1137-1139.

Ca i Y., Lu o Q., S un M., C orke H. (2004). Antioxidant activity and phenolic compounds of 112 traditional Chinese medicinal plants associated with anticancer. Life Sci., 74: 2157-2184. 
Ca o Z., Shi B., Zhang P., Chu W., Sun D., Tong M., Chen H., Guo X. (2015 a). Effects of Artemisia argyi on immune and antioxidative functions in broilers (in Chinese). Cereal Feed Ind., 11: 70-73.

C a o Z., Shi B., Zhang P., Chu W., Jing H., Ding Y., Gu o X. (2015 b). Effect of Artemisia argyi powders on growth performance, slaughter performance and meat quality in broilers (in Chinese). Cereal Feed Ind., 6: 56-59.

D e 11 e s R.M., X i ong Y.L., Tru e A.D., A o T., D a w s o n K.A. (2014). Dietary antioxidant supplementation enhances lipid and protein oxidative stability of chicken broiler meat through promotion of antioxidant enzyme activity. Poultry Sci., 93: 1561-1570.

Diaz P., Je ong S.C., Lee S., Khoo C., Koyyal a mudi S.R. (2012). Antioxidant and antiinflammatory activities of selected medicinal plants and fungi containing phenolic and flavonoid compounds. Chin. Med-UK., 7: 26-34.

Ha feman D., Sunde R., H o e kstra W. (1974). Effect of dietary selenium on erythrocyte and liver glutathione peroxidase in the rat. J. Nutr., 104: 580-587.

$\mathrm{Haj}$ at i H., Has s a nabadi A., A hmadian F. (2014). Application of medicinal plants in poultry nutrition. J. Med. Plants By-Prod., 3: 1-12.

H a 11 i w e 11 B., G u t t e r i d g e J.M.C. (2015). Free radicals in biology and medicine. Oxford University Press, New York, USA.

Hassan F.A.M., Roushdy E.M., Kishawy A.T.Y., Zaglool A.W., Tukur H.A., $\mathrm{S}$ a a d e $1 \mathrm{~d}$ in I.M. (2019). Growth performance, antioxidant capacity, lipid-related transcript expression and the economics of broiler chickens fed different levels of rutin. Animals, 9: 7.

Huang H.C., Wang H.F., Yih K.H., Chang L.Z., Chang T.M. (2012). Dual bioactivities of essential oil extracted from the leaves of Artemisia argyi as an antimelanogenic versus antioxidant agent and chemical composition analysis by GC/MS. Int. J. Mol. Sci., 13: 14679-14697.

J e ong M.A., L e e K.W., Yoon D.Y., L e e H.J. (2007). Jaceosidin, a pharmacologically active flavone derived from Artemisia argyi, inhibits phorbol-ester-induced upregulation of COX-2 and MMP-9 by blocking phosphorylation of ERK-1 and -2 in cultured human mammary epithelial cells. Ann. N. Y. Acad. Sci., 1095: 458-466.

L a m b eth J.D. (2004). NOX enzymes and the biology of reactive oxygen. Nat. Rev. Immunol., 4: $181-189$

Lan M.B., Zhang Y.H., Zheng Y., Yuan H.H., Zhao H.L., Gao F. (2010). Antioxidant and immunomodulatory activities of polysaccharides from moxa (Artemisia argyi) leaf. Food Sci. Biotechnol., 19: 1463-1469.

Li u M., Ga o R., Meng Q., Zhang Y., B i C., S h an A. (2014). Toxic effects of maternal zearalenone exposure on intestinal oxidative stress, barrier function, immunological and morphological changes in rats. PloS One, 9: e106412.

L i vak K.J., S chmittgen T.D. (2001). Analysis of relative gene expression data using real-time quantitative PCR and the $2^{-\triangle \Delta C T}$ method. Methods, 25: 402-408.

L v J., D u a n J., S he n B., Y in Y.Y. (2013). Caffeic acid esters from Artemisia argyi and their antioxidant activities. Chem. Nat. Compd., 49: 8-11.

M c C or d J.M., F ri d o v i c h I. (1969). Superoxide dismutase an enzymic function for erythrocuprein (hemocuprein). J. Biol. Chem., 244: 6049-6055.

National Research Council (1994). Nutrient Requirements of Poultry. 9th rev ed. Washington DC, National Academic Press.

P l a c e r Z.A., C u s h m a n L.L., J o h n s o n B.C. (1966). Estimation of product of lipid peroxidation (malonyldialdehyde) in biochemical systems. Anal. Biochem., 16: 359-364.

S a h a S.K., B r e w e r C.F. (1994). Determination of the concentrations of oligo-saccharides, complex type carbohydrates, and glycoproteins using the phenol-sulfuric acid method. Carbohyd. Res., 254: $157-167$.

S a la mi S., Guingu in a A., A g bo ol a J., O mede A., Agbon lahor E., Ta y y ab U. (2016). Review: In vivo and postmortem effects of feed antioxidants in livestock: a review of the implications on authorization of antioxidant feed additives. Animal, 10: 1375-1390.

Sh en C.Y., Wang T.X., Z hang X.M., Ji ang J.G. (2017). Various antioxidant effects were attributed to different components in the dried blossoms of Citrus aurantium L. var. amara Engl. J. Agr. Food Chem., 65: 6087-6092. 
S u n H., J i a n g S., M u P., Q i D. (2009). In vivo antioxidative capacities of rapeseed meal polysaccharides. J. Food Agric. Environ., 7: 97-102.

S u rai P. (2014). Polyphenol compounds in the chicken/animal diet: from the past to the future. J. Anim. Physiol. Anim. Nutr., 98: 19-31.

S u ra i P., Fis in in V. (2015). Antioxidant-prooxidant balance in the intestine: applications in chick placement and pig weaning. J. Vet. Sci. Med., 3: 16.

Valko M., Leibfritz D., Moncol J., Cronin M.T., Mazur M., Telser J. (2007). Free radicals and antioxidants in normal physiological functions and human disease. Int. J. Biochem. Cell Biol., 39: 44-84.

Wa 1 ker J.M. (2009). The bicinchoninic acid (BCA) assay for protein quantitation. In: The protein protocols handbook. Humana Press, Totowa, NJ, pp. 11-15.

Wan X.L., Niu Y., Zheng X.C., Huang Q., S u W.P., Zhang J.F., Zhang L.L., Wang T. (2016). Antioxidant capacities of Artemisia aпnиa L. leaves and enzymatically treated Artemisia annua L. in vitro and in broilers. Anim. Feed Sci. Tech., 221: 27-34.

Z h a n g L.B., L v J.L., C h en H.L., Y an X.Q., D u a n J.A. (2013). Chemical constituents from Artemisia argyi and their chemotaxonomic significance. Biochem. Syst. Ecol., 50: 455-458.

Zhang H., Chen Y., Li Y., Yang L., Wang J., Wang T. (2014). Medium-chain TAG attenuate hepatic oxidative damage in intra-uterine growth-retarded weanling piglets by improving the metabolic efficiency of the glutathione redox cycle. Br. J. Nutr., 112: 876-885.

Zhang P., Shi B., Li T., Xu Y., Gu o X., J in X., Yan S. (2018). Immunomodulatory effect of Artemisia argyi polysaccharide on peripheral blood leucocytes of broiler chickens. J. Anim. Physiol. Anim. N., 102: 939-946.

Zhao F., Shi B., S un D., Chen H., Tong M., Zhang P., Guo X., Yan S. (2016). Effects of dietary supplementation of Artemisia argyi aqueous extract on antioxidant indexes of small intestine in broilers. Anim. Nutr., 2: 198-203.

Received: 23 IX 2019

Accepted: 3 III 2020 